\title{
LA RECONSTRUCCIÓN DEL CONSEJO REGULADOR DE LA DOC RIOJA TRAS LA GUERRA CIVIL
}

\author{
César Luena López ${ }^{1}$ \\ Universidad de La Rioja \\ cesarluena@gmail.com
}

RESUMEN: El organismo medular de la DOC Rioja, su consejo regulador, tuvo que reconstruirse tras la guerra civil. Nacido en 1925 de la mano de la dictadura de Primo de Rivera, conoció una etapa democrática durante la Segunda República y el fracaso del Estatuto del Vino. Tras la guerra, vivió dos etapas diferenciadas. La propia de reconstrucción, que fue de rivalidad institucional entre el Consejo y el Sindicato Nacional de la Vid y el Vino, y la última de consolidación, tras el reglamento de 1953. Antonio Larrea, hombre protagonista en las decisivas décadas centrales del siglo XX para la DOC Rioja, actuará, a su pesar incluso, como un factor clave y determinante en la tarea de volver a poner en pie el Consejo Regulador.

Palabras clave: Consejo Regulador, DOC Rioja, Antonio Larrea, Víctor Pérez y Díaz de Mendívil, Estatuto del Vino, Criadores-Exportadores, Sindicato Nacional de la Vid y el Vino, reglamento, C.O.S.A.

\section{THE RECONSTRUCTION OF THE RIOJA DOC REGULATORY COUNCIL AFTER DE CIVIL WAR}

ABSTRACT: The core organ of the Rioja DOC, its regulatory council, had to be rebuilt after the civil war. Created in 1925 under the dictatorship of Primo de Rivera, it experienced a democratic stage during the Second Republic and the failure of the Wine Statute. After the war, there were two differentiated stages. The first stage was that of reconstruction, which was dominated by the institutional rivalry between the Council and the National Union of the Vine and the Wine, and the last stage was that of consolidation, after the regulation of 1953.

1. Doctor por la Universidad de La Rioja. 
Antonio Larrea, who had a protagonist role in the decisive central decades of 20th century for the DOC Rioja, acted as a key and decisive factor in the task of reinstating the Regulatory Council.

Keywords: Regulatory Council, Rioja DOC, Antonio Larrea, Víctor Pérez and Díaz de Mendívil, Wine Statute, Breeder-Exporters, National Vine and Wine Union, regulation, C.O.S.A.

Recibido: 14 de Abril de 2016

Aceptado: 14 de Junio de 2016

\section{Los difíciles años treinta}

La Segunda República se implantó en La Rioja con una gran alegría, a la que parecía sumarse también el Rioja, pues la de 1931 fue una excelente cosecha, en calidad y cantidad. Las grandes bodegas históricas habían tenido enormes beneficios en la década de los veinte, cuando el poderoso sector bodeguero logró la creación de la Denominación de Origen y el Consejo Regulador, únicos en España. Como se recoge en El Rioja histórico, no es anecdótico que, en 1929, de los 118 automóviles matriculados en la provincia, 65 lo fueran en Logroño, 14 en Haro y 12 en Calahorra, mientras en Nájera, Santo Domingo y Arnedo sólo se inscribieron tres. El Rioja tiraba todavía del complejo agro-industrial${ }^{2}$. Por otra parte, a nivel general, como explica el profesor Emilio Barco, "la renta nacional de España se dobló en el primer tercio del siglo XX, produciéndose, además, lo que García Delgado, denomina "crecimiento económico moderno"s, y que asocia a cambios significativos en los métodos fabriles y en la propia estructura de cada uno de los sectores y a las transformaciones demográficas que se reflejan, especialmente, en el aumento de la esperanza de vida (de 35 a 50 años) y en el proceso de urbanización (se duplica el censo de las principales capitales) ${ }^{\prime \prime 4}$. Todos estos factores de modernización son observables en varios polos de la modernización riojana, como son las comarcas de Haro, Calahorra y Logroño. En el sector agrario, se aprecia igualmente un avance efecto de la las mejoras técnicas, con un uso muy generalizado del empleo de abonos inorgánicos y, por ende, un aumento de la productividad, a causa de la disminución de brazos en el mundo rural, que

2. Gómez Urdáñez, J. L. (dir.) (2000), El Rioja histórico. Consejo Regulador, Logroño, pp. 93 99. Véase también www.bermemar.com.

3. García Delgado, J. L. (coord.) (1976), La cuestión agraria en la España contemporánea. EDICUSA, Madrid.

4. Barco Royo, E., (2013), Factores determinantes del funcionamiento económico del sector vitivinícola en la Denominación de Origen Calificada Rioja (DOCa Rioja) y su adaptación a los cambios en el entorno económico. Tesis doctoral, Universidad de La Rioja. 
produjo un cierto alivio en los grandes poblachones de pobres de La Rioja Baja, donde, como ha explicado el profesor Gómez Urdáñez, se producían concentraciones, como la de Autol, por ejemplo, en las que se comprueba la ley histórica "el crecimiento demográfico sin crecimiento económico es una fábrica de pobres" ${ }^{\prime \prime}$. Aún con todo, la República no se proclamaba en una Rioja pobre, ni en una España pobre, y no es este el lugar de recurrir a comparaciones con otros países de Europa, en los que la recuperación de la crisis finisecular había sido igualmente costosa y el éxito económico menor a causa del retroceso que supuso la Primera Guerra Mundial. Como demostraron Domingo Gallego y otros historiadores del Grupo de Estudios de Historia Rural, la productividad en la producción de cereales en España, en secano, estaba muy por encima de la de cualquier país europeo. Y en cuanto a La Rioja, el profesor Domingo Gallego dejó claro en su tesis doctoral que la agricultura riojana estaba a la altura de 1931 en las mejores condiciones de producción, comercialización e innovación ${ }^{6}$.

Así pues, la República, con su programa reformista y con la iniciativa de captar a la pequeña burguesía agraria de los pueblos, iba a comenzar con optimismo los dos postulados más interesantes para La Rioja: por una parte, la reforma agraria, un proyecto que venía desde los tiempos de los ilustrados Olavide, Campomanes y Jovellanos, y que todo el mundo juzgaba que era prioritario, y por otra, la reorganización del sector del vino y los alcoholes, pues era generalizado que el sector necesitaba una legislación que evitara fraudes, definiera los diferentes aspectos implicados -viticultores, remolacheros, fabricantes de alcohol- y continuara con la demarcación de las regiones vitivinícolas mediante las Denominaciones de Origen ${ }^{7}$. Sin embargo, los dos proyectos iban a encontrar grandes dificultades, entre ellas la irrupción de la crisis económica que iba a azotar Europa. A la excelente cosecha de 1931, que sobrepasó los 90 millones de litros ${ }^{8}$, casi el doble que la anterior, le sucedió la del 32, una de las peores del siglo. Además, en ese año llegaron a Europa los efectos de la crisis de la bolsa de Nueva York en 1929, que en España iban a impedir la puesta en práctica de los proyectos republicanos reformistas, especialmente en el mundo rural, donde el paro y la disminución de las inversiones comenzaron a ser el principal problema. El viñedo, que necesita una fuerte mano de obra estacional, sufrió las tensiones provocadas por las peticiones de más jornal de los sindicatos, enfren-

5. Gómez Urdáñez, J. L. (dir.) (2010), Autol histórico, Logroño.

6. Gallego Martínez, D. (1987), “El factor agrario riojano, 1855 1935. De la especialización vitícola a la diversificación de la producción agraria". Brocar n 12, pp. 4588 . Véase también Garrabú R., Barciela C., y Jiménez Blanco J. L., (1986), Historia agraria de la España contemporánea. Tomo 3 El fin de la agricultura tradicional (1900-1960), Crítica, Barcelona.

7. Cabrera, Mercedes (1983), La patronal ante la II República: organizaciones y estrategia (1931-1936), Siglo XXI, Madrid.

8. Nótese que esta producción no se volverá a alcanzar hasta 1952. 
tadas a los propietarios del viñedo y bodega rural, que eran pequeños propietarios en una abrumadora mayoría y no podían aceptar, pues también caía la demanda, especialmente la que se sostenía por la exportación a través de las grandes bodegas. La Cámara de Comercio reflejaba así el problema en la memoria de 1932: "La política de contingentes y las dificultades de orden arancelario que, como consecuencia del proteccionismo de ciertos países, nacido por la ineludible necesidad de defender sus respectivas producciones, redujeron el volumen del intercambio comercial, se hicieron sentir en la demarcación de esta Cámara, que cuenta con típicos productos de exportación como son frutas, vinos y conservas, sufriendo más que otras regiones españolas las consecuencias del déficit en nuestro comercio exterior"

En efecto, el cierre de mercados exteriores afectó de lleno al vino. Francia impuso los contingentes, haciendo pasar las exportaciones españolas de más de dos millones de hectolitros en 1931 a 870.000 al año siguiente ${ }^{10}$. En suma, como ha sintetizado Francisco Comín, "la crisis que ahogó a la República se caracterizó por el aumento del desempleo, la caída de precios y el descenso de la producción $n^{\prime 11}$. Entre 1929 y 1933, las exportaciones españolas cayeron un $30 \%$. El Rioja parecía menos afectado, con una caída del total exportado del $15 \%$, pero la crisis había incidido drásticamente en la línea abierta por las bodegas de calidad, pues el embotellado se redujo hasta una tercera parte. Desde entonces el Rioja entró en una dinámica que costaría décadas frenar, la de la exportación de graneles, una actividad muy remuneradora, pero que era incompatible con la lucha por la calidad, como reconoció años después el que iba a manejar las riendas de la restauración del Consejo Regulador desde su puesto de director de la Estación Enológica, Antonio Larrea. El ingeniero Larrea, que tanto iba a hacer por el Rioja después de la guerra civil, se mostró durante muchos años incapaz de proponer una solución, que sólo llegaría en 1991 tras la concesión de la Calificada. "Para muchos hombres representativos del Rioja, el granel pesaría durante décadas como un destino insuperable ${ }^{12}$.

\section{El fracaso del Estatuto del Vino de 1932}

Como ha explicado el profesor Comín, la crisis económica se presentó en España con algún retraso y con cierta moderación, pero reflejaba el atraso de su

9. El Rioja histórico (2000), p. 93.

10. Cabrera, M. (1983).

11. Comín, Francisco (2010), "Política y Economía: los factores determinantes de la crisis económica durante la Segunda República (1931 1936)", Historia y Política, n² 26, julio diciem bre, pp. 4779.

12. El Rioja histórico (2000). Hay que recordar que todavía hoy, aunque por circuitos dis tintos al de los vinos protegidos, España exporta grandes cantidades de vino a granel. $Y$ es que todavía el "vino de las tabernas", hoy el "vino en tetrabrick", es muy remunerador. 
economía, reflejado en el enorme peso de la agricultura. También el proteccionismo arancelario y la depreciación de la peseta contribuyeron a aislar a la economía española del exterior, lo que era grave para el Rioja, mientras la política laboral y social incrementó los costes salariales y creó enfrentamientos sociales, empeorando las cuentas de resultados y las expectativas empresariales, lo que también perjudicaba el clima político y creaba una enorme inestabilidad ${ }^{13}$. En esas condiciones y en el año de la pésima cosecha de 1932, Marcelino Domingo, ministro de Agricultura, Industria y Comercio de la República, promulgó el Estatuto del Vino, un intento de reorganizar el sector vitivinícola español que resultó ser un estrepitoso fracaso al enfrentar a varios sectores implicados en la elaboración de alcohol, los vinateros y los azucareros, mientras no lograba ordenar el sector de cara a una exportación cada vez más restringida por los gobiernos europeos, que imponían fuertes tasas arancelarias.

El Estatuto del vino fue precedido, el 8 de septiembre de 1932, por el primer decreto firmado por el ministro Marcelino Domingo. Al año siguiente, el 26 de mayo de 1933, era convertido en Ley y sería conocido como el primer Estatuto del Vino y de los alcoholes. Al margen del largo entramado legal, que no es lugar para desentrañar y que ha sido abordado por expertos ${ }^{14}$, el Estatuto afectaba de lleno a la composición del Consejo Regulador, que en 1926 había sido constituido como un instrumento legal del grupo de presión de los bodegueros de Haro y de la oligarquía logroñesa ligada a las Bodegas Franco-Españolas ${ }^{15}$. Lo habían solicitado al dictador Primo de Rivera nada más llegar al poder por medio de Martínez Lacuesta, el presidente de la Asociación de Exportadores de Vinos de La Rioja, que englobaba a la práctica totalidad de los Criadores-Exportadores de La Rioja Alta. Antes el dictador había recibido una carta del presidente de las Cooperativas de los Sindicatos Católicos de Haro, Felipe Ruiz Castillo, que pedía medidas contra el fraude, en noviembre de 1923, pero que en realidad, manifestaba otras preocupaciones bien distintas a las de los grandes bodegueros $^{16}$. El Consejo Regulador de 1926 sería fruto de la imposición de los grandes bodegueros, que iban a estar respaldados por la Cámara de Comercio de Logroño, pero por esa razón, al Ilegar la República era un organismo poco operativo, que sería transformado de raíz en el Estatuto del Vino.

13. Ídem.

14. Seguimos la mejor publicación al respecto, la tesis doctoral publicada: Coello Martín, C. (2008), Las Bases Históricas y Administrativas del Derecho Vitivinícola Español. El Sistema jurídico de las Denominaciones de Origen. Ed. Instituto Andaluz de Administración Pública, Sevilla.

15. Gómez Urdáñez, J. L., Luena, C., Bustos, S. y Juaneda, E. (2015), 125 años. Bodegas Franco-Españolas, testigo de la historia de Logroño, Logroño.

16. Navajas Zubeldia, C. (1995), "Cosecheros contra comerciantes. Los antecedentes inme diatos de la creación del Consejo Regulador de la Denominación de Origen Rioja". Berceo, n 12, pp. 175188. 
La nueva ley reglamentaba las Denominaciones de origen atendiendo a "las variedades que cultiva y las condiciones climatológicas y geológicas que en ella concurren" y a la región "que impuso este nombre en el mercado nacional o extranjero". El Consejo Regulador iba a ser muy distinto al conocido. El número de sus miembros se reducía a siete, entre los que no estaban ya los cargos políticos ni era presidido por el presidente de la Diputación Provincial, sino por un técnico, el ingeniero director de la Enológica, o en su defecto, el Ingeniero jefe del Servicio Agronómico Provincial. Los demás miembros del consejo eran muy representativos, incluyendo a los sindicatos y a la patronal, representada por la conocida Asociación de exportadores presidida por Martínez Lacuesta. Cuando después de la guerra se intente restaurar el Consejo Regulador, la presidencia se mantendrá en el director de la Enológica, lo que no cambió hasta la Ley del Vino de 1970, mientras la representación la siguió ostentando la Asociación, ahora llamada de Criadores-Exportadores, encuadrada en el Sindicato Nacional de la Vid y el Vino, de Falange Española de la JONS, la misma organización que, como los sindicatos corporativos fascistas o salazaristas, encuadraba también a los productores ${ }^{17}$.

El Consejo Regulador democrático tuvo cada vez menos operatividad, no sólo por las dificultades internas y la ralentización de la organización -al llegar la Guerra Civil todavía no se había redactado el reglamento-, sino porque las malas cosechas y los bajos precios provocaron una gran inestabilidad social en los pueblos de mayor concentración de viñedos, en los que tanto durante la jornada revolucionaria del día 8 de diciembre de 1933, como a lo largo del octubre revolucionario de 1934, ocurrieron graves alteraciones y huelgas ${ }^{18}$. Luego llegó la sublevación militar, la represión -unas 2.000 personas fueron asesinadas en cunetas y descampados en La Rioja- y la movilización de los jóvenes, reclutados para el frente, con el consiguiente embargo de camiones y automóviles y de

17. Antonio Larrea estaba familiarizado con la situación en Portugal, adonde viajó junto a Concepción Llaguno los días 11 y 12 de junio de 1967 para asistir al Primer Congreso de la Unión Internacional de Enólogos, que congregó a enólogos de España, Francia, Italia, Grecia y Argentina. Seguramente, pudo reparar en el parecido entre la Junta Nacional do Vinho, presidi da por Manuel Cotta Dias y el Sindicato Nacional del Vino que aquí tenía siempre al lado en el Consejo Regulador, pues como él decía, el consejo era un apéndice del Sindicato; incluso compartía el mismo Secretario, Enrique del Río Villarejo. El viaje de Larrea, documentado en FL Vivanco, caja 26.

Sobre el caso de Portugal, Freire, Dulce (2014, en prensa), Dulce FREIRE, Université de Lis bonne, " "Seigneurs de la vigne et du vin ", I'organisation corporative, groupes d'intérêt et modernisation de l'agriculture dans les dernières décennies de la dictature (Portugal, 1945 1974)", en prensa en actas del Colloque international sur La construction de la grande propriété viticole en France et en Europe, XVle XXe siècles. Bordeaux, 30 y 31 de mayo de 2013. Puede verse el resumen en http://gomezurdanez.com/proprieteviticoleres.pdf.

18. Gil Andrés, Carlos (2000), Echarse a la calle: amotinados, huelguistas y revolucionarios (La Rioja, 1890-1936), Zaragoza. 
caballos y mulos con destino al ejército de Franco. La vendimia de 1936 fue catastrófica, entre el luto de millares de familias -también las que ya habían perdido a algún miembro en los frentes de batalla-, el hambre y la falta de brazos. Vino amargo como las lágrimas de los españoles que se enfrentaban al más negro destino: la Guerra Civil y la brutal dictadura militar. Las bodegas riojanas, como las Franco-Españolas, quedaron convertidas en grandes almacenes de vinos de todas las procedencias, cuyo destino era el frente, los soldados del ejército nacional, por lo que fueron administradas por autoridades militares ${ }^{19}$.

\section{1941-1953: la rivalidad institucional. Sindicato versus consejo}

Tras la Victoria, había que reorganizar el sector y pronto se recordó el Consejo Regulador, aunque pasaron años en que no se notó su falta, pues no existía la razón de ser primordial de su actividad, que era la exportación. El aislamiento del mundo dejaba en la inoperancia al Consejo y a EVE, las instituciones que iba a presidir un joven Antonio Larrea ${ }^{20}$, que llegaba a un Haro que nada se parecía al Haro alegre de los años veinte y treinta. Además, el funcionario del Estado se iba a encontrar delante al Sindicato, a la Falange, que había fundado la delegación provincial del Sindicato Nacional de la Vid y el Vino el 1 de enero de 1941 en Rioja, un organismo que encuadraba a todo el sector y a todas sus instituciones, incluida la Enológica y el Consejo Regulador, bajo el mando del Jefe Provincial, Víctor Pérez y Díaz de Mendívil, gerente muchos años de la bodega CVNE, luego sustituido por Marcelo Frías Artacho, el que tanta relación tuvo con Larrea en todos los organismos.

Eran hombres duros, profundamente falangistas, que contrastaban en tantos aspectos -incluso de la vida diaria- con Antonio Larrea, hombre humilde, muy religioso, tímido y exento de cualquier vicio, en comparación con estos hombres fuertes y dominantes. Como leemos en El Rioja histórico, "en 1949, cuando hacía dos años que se había aprobado el reglamento por el que renacía el Consejo Regulador de la Denominación de Origen Rioja, los Criadores-Exportadores volvían a demostrar quién mandaba y reivindicaban la autonomía del Sindicato Provincial de la Vid nada menos que para "controlar el uso de marcas colectivas y denominaciones de origen". Eran 24 empresas las que conformaban el subgrupo de Criadores-Exportadores en los años cuarenta y por tanto, imponían su dictado en las provincias de Logroño, Álava, Burgos y parte de la de Navarra, y para el

19. Gómez Urdáñez, J. L., Luena, C., Bustos, S. y Juaneda, E. (2015), 125 años. Bodegas Franco-Españolas, testigo de la historia de Logroño, Logroño.

20. Ver Luena López, C. (2015), "El vino de Rioja y su expansión desde la posguerra hasta 1970: Antonio Larrea, el hombre decisivo", en Brocar, Cuadernos de investigación histórica, $\mathrm{n}^{\circ}$ 39, pp. 249281. 
subsector específico de la exportación, en toda la zona norte de España, comprendiendo Aragón, Rioja y Navarra, con capitalidad en Logroño.

En esas circunstancias, bajo el control absoluto de Falange, renacía -de iure- el Consejo Regulador, que en 1947 se dotaba de un nuevo reglamento ${ }^{21}$. La realidad imponía que un hombre como Larrea se hallara al frente, de manera obligada, un hombre que nunca hubiera querido estar ahí, pero que quizás precisamente por eso, supo hacer -incluso no haciendo- que esos hombres fuertes se entendieran con los empobrecidos viticultores y renaciera el "pacto entre desiguales", al que debemos que el Rioja siga siendo el resultado de aquel cultivo social y poblador.

Para entender el reto al que se enfrentaba Larrea en 1953 hay que mirar atrás, casi una década antes, cuando el falangista Sindicato Nacional de la Vid y el Vino, constituido el 1 de enero de 1941, y las autoridades locales intentaron "resucitar" el Consejo Regulador. Son conocidos los hechos, que se iniciaron muy al estilo más populista del Régimen mediante convocatoria en el diario Nueva Rioja el 14 de diciembre de 1944 con proclamas como la siguiente:

"Viticultor riojano:

La protección de denominación de origen 'Rioja' equivale a:

1. Revalorizar los vinos riojanos

2. Aumentar las exportaciones de calidad

3. Crear nuevos tipos

4. Cuidar con esmero la crianza de los existentes

5. Conquistar, para La Rioja y España un prestigio comercial de primer orden ¡Une tu esfuerzo al de la Organización Sindical!

¡Exige que tu Hermandad esté presente en la Asamblea de vitivinicultores que se celebrará en Logroño el próximo día 19!"22.

De la asamblea del 19, celebrada en el Cinema Social -todavía existe la sala en la calle Calvo Sotelo-, salió el acuerdo "por inmensa mayoría" de "solicitar del Ministerio de Agricultura que ordenase la formación de un nuevo Consejo Regulador en cumplimento de la Ley"23. Con bastante rapidez, el 9 de marzo de 1945 se celebraba en el Ayuntamiento de Logroño la constitución del consejo, cuya presidencia tenía que asumir un recién llegado Larrea, y el 5 de junio se enviaba al Ministerio el reglamento redactado por presidente y vocales, que no sería aprobado hasta dos años después, por Orden de 28 de abril de 1947, tras numerosas rectificaciones, que disgustaron mucho al Sindicato ${ }^{24}$. Quizás por esa

21. El Rioja histórico (2000), pp. 100109.

22. El Rioja histórico (2000), p. 103.

23. Ídem, p. 105.

24. Coello Martín, C. (2008); Barco Royo, E. (2013). 
razón, o porque el Sindicato -a las órdenes de Víctor Pérez y Díaz de Mendívil, el hombre fuerte-, se había fortalecido tras las elecciones de 1947, o porque, con consejo o sin consejo, la economía española no dejaba de hundirse y el viñedo no alcanzaba los mínimos de rentabilidad, el hecho es que las ilusiones de 1944 se desvanecieron. Larrea lamentó en numerosos escritos la situación y dejó correr la pluma, a veces de una manera poco prudente, pues atinaba cuando cifraba la causa de que el consejo no funcionara en la presión de los grandes, los Criadores-Exportadores -23 bodegas que imponían su ley-, que además estaban todos encuadrados en el Sindicato, cuyas reuniones eran la "contra" de las que él podía mantener en el Consejo Regulador, pues obviamente, los vocales eran también miembros del Sindicato, en cabeza su jefe, Pérez y Díaz de Mendívil25.

Estaba claro que los exportadores criadores, los hombres fuertes del Sindicato de la $\mathrm{Vid}^{26}$, se oponían frontalmente a que funcionara el consejo en cuanto vieron el contenido del reglamento, sobre todo el punto de la limitación de entrada de vinos de fuera para mejorar sus vinos -aunque estaban rotundamente en contra de quienes utilizaban la marca Rioja para vinos que no lo eran- y más aún, el de la financiación, que debía correr por su cuenta ${ }^{27}$. Iban a ser ellos los que tenían que pagar nada menos que por hacer lo que ya hacían y además, por todo lo que imponía el reglamento del 47, que era lo que sigue: "Son fines del Consejo Regulador: la defensa y fomento de la industria vitivinícola de la zona Rioja; evitar la falsificación y adulteración de los vinos Rioja, así como la usurpación de la denominación de origen; vigilar la elaboración y el viñedo para que las prácticas vitivinícolas sean perfectas y con arreglo a los procedimientos característicos de estos vinos, procurando divulgar los mejores métodos de obtención de los mismos; expedir los certificados de origen y los precintos de garantía; organizar la propaganda genérica de la denominación de origen, así como proponer cuantas medidas juzgue convenientes para la mejor defensa de los intereses generales de la zona Rioja; vigilar los mercados nacionales y extranjeros, procurando que los productos lanzados a los mismos sean de clase inmejorable, y aplicar el presente reglamento." Para eso había que hacer un precinto con la marca Rioja -y Larrea logró que se hiciera- y había que aceptar que sólo "cuando lo aconsejaren las

25. AHPLR, Fondo AISS, caja 585.

26. Ortiz Rodríguez, José Luis, (2000), "El Sindicato Nacional de la Vid", en Maldonado Rosso, Javier y Ramos Santana, Alberto, Actas del I Encuentro de Historiadores de la Vitivinicultura Española, Puerto de Santa María.

27. Los motivos de la oposición, en un acta que se conserva de la reunión de 21 de enero de 1948, en que los Criadores Exportadores se niegan a inscribirse y definitivamente abando nan el consejo. El acta motivo carta de Larrea a Víctor Pérez y Díaz de Mendívil en la que el presidente recordaba al jefe del Sindicato que él era un funcionario y que debía mantenerse al frente del consejo y cumplir sus obligaciones. El acta y la carta de Larrea a Pérez de Mendívil, de 4 de febrero de 1948, FL Vivanco, caja 18. 
necesidades del comercio interior y exterior" el consejo podría autorizar "la introducción en las bodegas de crianza de vinos similares de otras procedencias, con el único fin de practicar operaciones enológicas y para que en añadas defectuosas pueda establecerse la normalidad del vino". Ni siquiera se aceptaba el porcentaje del $20 \%$ como límite a los vinos de fuera que los Criadores-Exportadores habían fijado en el reglamento que enviaron al Ministerio ${ }^{28}$.

Para muchos, era ofensivo, pero para todos, incluido Larrea, era una imposición sin fundamento teniendo en cuenta cómo estaba La Rioja. Aunque la exportación iba a empezar a reanudarse, todavía no se podía confiar en que el vino elaborado rutinariamente y sin mejora alguna, en viñedos mal cultivados, pudiera superar los "dientes de sierra", los altibajos no solo en cantidad, sino en grado y color de cosechas muy deficientes que si no se "alimentaban" con vinos de fuera arruinarían todavía más a los viticultores. Los malos años de mildiu -que fueron muchos a causa de la falta de fitosanitarios- provocaban que hubiera uvas que no llegaban ni a los 10 grados, así que, o se permitían esas "operaciones enológicas", o definitivamente el sector acababa en la ruina. Las posiciones eran tan encontradas que Larrea escribirá tras una reunión en la que se discutió fuertemente el inaceptable reglamento: "Visto lo irreconciliable de los criterios sustentados y faltando la opinión escrita de tres de los seis vocales, el que suscribe no juzgó procedente convocar a una nueva reunión para discutir los mismos temas, antes bien juzgó oportuno, elevar un informe a la superioridad, dilatándose el plazo de envío hasta el presente por causas totalmente ajenas a su voluntad". Es decir, que Larrea no se atrevió a involucrarse en una lucha que veía perdida y metió los papeles en un cajón hasta la fecha en que firmó y envió el informe que tenía pensado hacer y que terminó con su firma el día 21 de julio de $1948^{29}$.

¿Cuáles eran las dificultades? Además de las expuestas, Larrea veía fundamentalmente dos: una, el sostenimiento económico del Consejo Regulador, y dos, el impuesto de Usos y Consumos. Sin esas dos fuentes de financiación, "el Consejo Regulador se convierte automáticamente en un organismo totalmente inútil". En cuanto al sostenimiento económico, los viticultores se negaban a colaborar, mientras en el asunto de Usos y Consumos, que gravaba los vinos embotellados, se había ampliado por Orden de 30 de diciembre de 1947 a "todos los vinos" que salgan de La Rioja. Finalmente, Larrea pedía revisar el reglamento y ante todo "armonizar los intereses de viticultores y exportadores". Acompañó el informe con oficios de los Sindicatos, de los Criadores-Exportadores y con un acta de la última sesión que Larrea había celebrado con los miembros del Consejo Regulador el 20 de febrero de 1948, en que dio cuenta de toda

28. Véase Coello Martín, C. (2008), Barco, E. (2013). El reglamento, en FL Vivanco, caja 18.

29. FL Vivanco, caja 18. Véase también AEVEH, memoria de 1948, caja 1102. 
la información de que disponía. Pérez y Díaz de Mendívil tensionó la sesión que discurrió con una total falta de acuerdo, pues concitó las críticas de los otros sectores, incluido el de Rioja Alavesa, que defendía el reglamento. Entre las críticas duras estaba también la que efectuó Rafael López de Heredia, que el 22 de marzo de 1948 escribía: "En el actual estado de cosas, el tal organismo (en referencia al consejo) no solamente no tiene razón de ser, sino que ni siquiera puede subsistir". El vocal de los viticultores Jesús Jiménez era todavía más drástico, y dijo rotundamente que a la vista de que "ha pasado el plazo de inscripción sin que nadie haya venido a inscribirse, ha de darse este Consejo Regulador por terminado su cometido" ${ }^{\prime 30}$.

La vida de este resucitado consejo fue tan irrelevante que no se conservan en los fondos del Consejo Regulador ni actas ni acuerdos -Larrea guardó actas muy breves de las reuniones de 21 de enero y 20 de febrero de 1948, ésta la última-, lo que teniendo en cuenta la minuciosidad de Larrea, que guardaba todo, nos permite asegurar que no se levantaron antes, seguramente ni hubo secretario que lo hiciera. Tampoco se han conservado en los fondos del Sindicato, depositados en el Archivo Histórico Provincial de La Rioja, ni se producían noticias en la prensa, a pesar de que Larrea quedó facultado para escribir.

La Cámara de Comercio de Logroño sí se hizo eco de la existencia del consejo, pero para Ilamarlo, en 1949, "organismo inoperante y sobre papel que aún no ha logrado iniciar su funcionamiento". Pero, para la Cámara, había algo peor y es que "produce efectos contrarios a los perseguidos por lo que al mercado nacional se refiere ${ }^{\prime \prime 31}$. A pesar de ello, la Cámara creía que el Consejo Regulador era "de todo punto indispensable para proteger las exportaciones, como garantía para el consumidor", pero se inclinaba por mejorar "la redacción de un reglamento adaptado a nuestras singulares y específicas condiciones, en lugar de intentar su funcionamiento con otro copiado del que mantienen en vigor otras regiones españolas de muy distintas características" ${ }^{\prime 32}$. La Cámara parecía desconocer que los Consejos Reguladores de otras denominaciones estaban igual, o peor si cabe, que el de Rioja. Quizás salvo Utiel-Requena y Penedés -con los que tanto se relacionó Larrea-, no funcionaba ninguno ${ }^{33}$.

En suma, como concluía drásticamente Larrea en su informe de 21 de julio de 1948, en "Propuestas de Solución", "el Consejo Regulador de la región Rioja

30. FL Vivanco, caja 18.

31. El Rioja histórico (2000), p. 108.

32. Ídem.

33. Piqueras Haba, Juan (1981), La vid y el vino en el País Valenciano, Valencia, Institución Alfonso el Magnánimo; Carrión, Pascual (1955), Breve historia de la Estación de Viticultura y Enología de Requena, Valencia, Ministerio de Agricultura, Pesca y Alimentación; Saumell Soler, Antoni, Arnabat Mata, Ramón y Romeu Rovira, Jordi (2003), Estació de viticultura i Enologia de Vilafranca del Penedès, 1903-2003, cent anys d'historia, Institut Catalá de la Vinya i el Vi. 
no existe (subrayado en el original) desde el momento que no se ha acogido a su protección ninguna bodega dentro del plazo oportuno, y si la inscripción era obligatoria, carece de medios coercitivos para obligar llevar a cabo la citada inscripción" ${ }^{\prime \prime 3}$.

En paralelo a esta defunción, sin embargo, el Sindicato Provincial gozaba de muy buena salud, como se puede comprobar por el monto de sus actividades de esos años. Como en todos los demás ramos, todo pasaba por el Sindicato (o por los Servicios Nacionales, como el Servicio Nacional del Trigo), es decir, por Falange, constituida en la columna vertebral de la vida económica y social todavía a fines de los cuarenta. En 1949, el jefe Pérez y Díaz de Mendívil elevaba al Secretariado Nacional de Sindicatos un informe que recogía la actividad de los diferentes "grupos" de su organización en la provincia de Logroño y que podemos ver en el siguiente cuadro:

TABLA 1. Sindicato Provincial de la Vid, el Vino, cervezas y alcoholes ${ }^{35}$.

\begin{tabular}{|l|c|r|r|r|r|r|}
\hline Grupo & $\begin{array}{c}\mathbf{n}^{\mathbf{0}} \\
\text { empresas }\end{array}$ & técnicos & administ. & Especialistas & $\begin{array}{r}\text { mano } \\
\text { obra }\end{array}$ & total \\
\hline Export & 26 & 17 & 111 & 78 & 648 & 854 \\
\hline Fab. Licor & 16 & 5 & 24 & 6 & 53 & 88 \\
\hline Fab. Alcohol & 15 & 1 & 4 & 16 & 39 & 60 \\
\hline Mayoristas vin & 47 & & 4 & & 18 & 22 \\
\hline Viticultores & & & & & & 11.500 \\
\hline Totales & 104 & 23 & 143 & 100 & 758 & 12.524 \\
\hline
\end{tabular}

Es el mundo del vino y la viña, "cultivo social", en cifras, a las que hay que añadir mujeres e hijos, que en el cómputo de la época se ocultaban bajo el "cabeza de familia", el que figura como "viticultor". Pero tan importante es constatar la actividad de ese año, 1949, que se reflejó así:

Informes y gestiones sobre necesidades reales de sulfato de cobre y azufre; necesidades de botellas para acondicionamiento de elaboraciones de vinos; necesidad de vagones para envíos de vinos destinados a exportación; intrusismo de especuladores en el mercado de frutos; la pretensión de ejercer coacciones cerca de los elaboradores de vinos de Rioja por la Mutua de Ultramarinos 'La Única'; regularización y legalización de los

34. FL Vivanco, caja 18.

35. AHPLR, Fondo AISS, caja 585. Informe del Sindicato de 24 de septiembre de 1949. 
impuestos y exacciones municipales que gravan los vinos; constitución del Consejo Regulador de la Denominación de Origen Rioja; supresión de la ley de Tasa del Vino; equiparación tributaria de Rioja a Navarra en fabricación de alcoholes; reajuste de tarifas ferroviarias; impuesto del $10 \%$ de Usos y Consumos gravatorio del vino; modificación de cambios de divisas y ordenación del mercado de orujos" ${ }^{\prime 36}$.

Por si no nos quedara claro hasta donde llegaba la mano del poderoso sindicato, Mendívil añadía: "de los datos anteriormente expuestos se desprende tanto la importancia social como económica de este Sindicato". En efecto, la tenía hasta el punto de arrogarse la "constitución del Consejo Regulador", que sin embargo, él mismo había paralizado.

Así pues, habrá que esperar a la siguiente tentativa, quizás también a que se definan más claramente las expectativas de la exportación, lo que comenzó a hacerse realidad en la medida en que España comenzó a firmar acuerdos comerciales bilaterales con los distintos países, primero con las repúblicas hispanoamericanas - la mayoría gobiernos autoritarios que iban a ser decisivos para que la España de Franco fuera reconocida por la ONU-, luego con los europeos $^{37}$, y sobre todo habrá que esperar a que el Sindicato vaya perdiendo influencia política en la medida en que otros sectores del Régimen, sobre todo los católicos, la vayan incrementando. Larrea, profundamente católico y activo como jefe de Acción Católica de Haro, no dice una palabra sobre el debate católicos-Falange, que sin embargo fue muy virulento en esos años, más aún cuando comenzaron los aires de renovación que darían lugar al Concilio Vaticano II, del que tampoco dice nada (como no dijo tampoco el mismísimo obispo de la diócesis, el franquista acérrimo Abilio del Campo y de la Bárcena, que felicitaba personalmente la Navidad a Larrea y esposa, pero que fue uno de los obispos más recalcitrantes contra la doctrina de renovación del Concilio $)^{38}$.

Pero Larrea nunca va plantear la lucha abierta, ni se va a sumar a ninguno de los bandos contendientes, ni se va a "posicionar" ideológicamente ${ }^{39}$. Por eso, mientras la situación política y económica y la coyuntura internacional no se definan en beneficio del Rioja y se necesite de nuevo el Consejo Regulador, la

36. Todo pasaba por el Sindicato. Véase "El Sindicato Nacional de la Vid" (2000).

37. Sobre el mantenimiento de acuerdos incluso durante la autarquía, véase Fernández Navarrete, Donato (2005), "La política económica exterior del Franquismo: del aislamiento a la apertura", Historia Contemporánea 30, pp. 4978.

38. Hermet, Guy (1985), Los católicos en la España franquista: los actores del juego político. Madrid, Centro de Investigaciones sociológicas. También mantuvo estrecha relación con el car denal Suquía. FL Vivanco, caja 123.

39. Así se lo dice, expresamente, a Pérez y Díaz de Mendívil en la carta de 4 de febrero de 1948: "espero que comprenderá usted mi posición, pues soy funcionario y por tanto, no me puedo poner rotundamente al lado de nadie". FL Vivanco, caja 18. 
labor de Larrea vuelve a ser la Enológica, donde año a año, dejó unas impresionantes memorias en las que reflejó todo lo importante acaecido para la vid y el vino y todo lo ocurrido en la Estación, en sus laboratorios, campos de experimentación y bodega.

\section{La consolidación: el reglamento de 1953}

La siguiente tentativa de resucitar el Consejo Regulador se produjo al amparo de la decisión ministerial de reformar el reglamento, que fue aprobado el 16 de abril de 1953 y publicado en el BOE el 23 de junio. El nuevo reglamento, que seguía manteniendo la presidencia en el ingeniero director de la Enológica, introducía cambios sustanciales que, de entrada, iban a permitir al Consejo Regulador iniciar la consolidación institucional, aunque fuera muy tímidamente todavía frente al Sindicato. La reforma regulaba los distintos registros necesarios para una eficaz vigilancia y, sobre todo, intensificaba las medidas de control en algunos aspectos básicos. Los precintos con la marca de la Denominación serían repartidos exclusivamente por el consejo, siguiendo las directrices del Ministerio de Hacienda. Pero lo más importante era que el reglamento abría la posibilidad de que el Consejo Regulador contara con veedores propios para vigilar el cumplimiento de sus fines. Dependerían del Ministerio de Agricultura, pero la propuesta de nombramiento de veedores la efectuaba el consejo, que corría con los gastos derivados de su actuación, a decir verdad, bien escasos. También es cierto que el número de veedores será tan escaso que veremos a Larrea alegrarse cuando se contrata jun veedor más! ${ }^{40}$

A pesar de las buenas intenciones del reglamento del 53, seguía existiendo la insalvable contradicción: el consejo carecía de una financiación adecuada para hacer frente a sus cometidos; además, a partir de ahora, se recortaban sus ingresos al acordarse la reducción del canon pagado por las bodegas en 50 céntimos menos por hectolitro en el vino destinado a la exportación y en 1,15 pesetas en el hectolitro que se vendía en el interior ${ }^{41}$. La situación no permitía albergar muchas esperanzas, así que el presidente Larrea no podrá tenerlas en algunos años.

No es éste el lugar para volver sobre un aspecto muy conocido, gracias a los trabajos de los profesores Carlos Coello y Emilio Barco y al pionero de Gómez Urdáñez, pero sí vamos a intentar verlo con los ojos de Antonio Larrea, tanto a través de la actas, conservadas en su archivo personal, hoy Fondo Larrea en el Centro de Documentación de la Fundación Vivanco de la Cultura del Vino, y en el archivo del Consejo Regulador de la DOC Rioja, como a través de sucintas notas que añadió, año a año, a la memoria anual de la Enológica. De toda esta

40. El Rioja histórico (2000), p. 110 y ss.

41. Coello Martín, C. (2008), El Rioja histórico (2000). 
documentación se desprende que Larrea "bajaba" a Logroño con muy poco optimismo, pues la normativa legal no acababa de aclararse y el consejo seguía teniendo muy pocas armas contra fraudes y abusos. Es cierto que en 1953 algo parecía haber cambiado, pero pronto se impondría la realidad, lo que el presidente sospechó desde el primer día. Había constituido el consejo en julio de 1953 y en diciembre se despachaba con un artículo en el diario Nueva Rioja que seguramente fue severamente juzgado por algunos bodegueros. Desilusionado y todavía inexperto, Larrea también se dejaba llevar por la inercia de la época y podía llegar a escribir lo siguiente para explicar por qué todavía no se había puesto en funcionamiento el Consejo Regulador de La Rioja y se respondía:

por dos razones, las dos dependiendo de malas cualidades del pueblo español, que las tiene, ya que no todo van a ser virtudes y buenas cualidades. La primera, la rebeldía innata del español a todo lo que suponga organización, disciplina, colaboración. Cree el labrador que haciendo las cosas aislado, sin apoyarse en otros, sin presentar un frente único, le va mejor y que así no le explotarán, no le engañarán; las consecuencias suelen ser fatales: no le engañan los empleados del estado, pero sí los almacenistas y comerciantes de toda índole. La segunda es el espíritu de picaresca que todo español tiene un poco metido en el cuerpo ¿Impedirle al elaborador sus pequeños trapicheos? ¿Obligarle a que todo el vino sea de buena calidad y que si sale algo malo, estropeado, con mal olor o sabor, no intente colarlo con lo bueno? Imposible. El labrador ha de tener las manos libres. Y las consecuencias se van viendo: el bajón más brutal de precios ha sido el del precio del vino; y vienen las súplicas y el poner precipitadamente en funcionamiento Consejos Reguladores y las medidas de protección y el solicitar que hasta las niñas de los colegios se les haga beber vino. Antes debieran haberse hecho las $\operatorname{cosas}^{42}$.

Así pues, el 12 de julio de 1953, Antonio Larrea constituyó el Consejo Regulador advirtiendo que la reunión tenía carácter de extraordinaria "puesto que al no funcionar normalmente el consejo no hubo fundamento suficiente para entrar en un periodo normal de convocatorias"43. Estaban en la reunión Jesús Jiménez Sáinz de Rozas (presidente de la C.O.S.A.), Cándido Ochoa Calahorra, Jesús Santiago Calleja, Rafael López de Heredia, Víctor Pérez Díaz de Mendívil y el que ya actúa como secretario Enrique del Río Villarejo, que lo es también del Sindicato. Se trataba antes de nada de implantar el reglamento que el Ministerio de Agricultura había publicado en el BOE el día 23 de junio y que afectaba a Criadores-Exportadores pero también a viticultores, a los que se convocará a

42. Publicado en Nueva Rioja, diciembre de 1953, recorte en AEVEH, memoria de 1953, caja 1095.

43. ACRDOC Rioja, Actas, acta de los días señalados. 
través de la C.O.S.A. y de las hermandades de Labradores. Los secretarios de las hermandades actuarán como agentes del Consejo Regulador, mientras Sáinz de Rozas y Ochoa Calahorra son delegados para que "establezcan el procedimiento más eficaz" para que los viticultores conozcan los objetivos del consejo.

Los puntos del orden del día venían marcados por la "superioridad", de manera que sólo había que desarrollarlos y, una vez constituido, el consejo debía aprobar un proyecto de presupuesto, el caballo de batalla de años anteriores. Larrea propone que se pida un crédito para empezar, asunto del que queda encargado personalmente. Se acuerda pedir 25.000 pesetas. También se acuerda la primera campaña de prensa, de la que se encarga a Pérez y Díaz de Mendívil, todavía el hombre fuerte del Sindicato, y la primera nueva "marca", que ha de sustituir a la de 1929. Larrea comunica que tiene redactadas unas notas para hacer el primer reglamento de funcionamiento interno del consejo. No parece haber habido tanta oposición como en años atrás, pero Larrea seguía sin mostrar ningún entusiasmo.

La siguiente reunión es de 13 de agosto de $1953^{44}$. Parecen estar todos satisfechos, pues de los 24 Criadores-Exportadores del Grupo del Sindicato se han inscrito ya 22. Se agradece la buena disposición de todos los organismos, incluidas las CC.OO.SS.AA.s, es decir, los sindicatos falangistas, de Álava y Navarra. Se comunica el éxito de la campaña de publicidad y la realización de los primeros nombramientos de veedores. También reciben la película "Jerez" que estudiarán para ver en qué pueden mejorar el Rioja. El Ministerio acepta oficialmente el nombramiento como secretario de Enrique del Río Villarejo, que lo es también del Sindicato. También se comunica que el consejo tendrá sede, con salón de sesiones y un despacho, en el edificio de Sindicatos de la calle Milicias, de Logroño $0^{45}$.

El 11 de septiembre se celebra una nueva reunión, con un vocal más, Carlos Laorden Sarriá. Sigue la campaña de prensa en Nueva Rioja. Todavía por las resistencias al sistema métrico en el mundo del vino -que continúan- se acuerda no poner en la propaganda que los agricultores pagarán de canon 0,35 pesetas. por Hl., "sino el equivalente de esa cantidad por cántara, teniendo en cuenta que la cántara es 16,04 litros". Siguen varias reuniones, sin tensiones; asiste el representante de la C.O.S.A. de Âlava, no así el de Navarra. En sesión de 11 de febrero de 1954 se encarga al sr. Santiago que haga las contraetiquetas; también se recibe lista de los aspirantes a veedores, son 9. Hay mucho movimiento organizativo, sin duda, se están poniendo las bases de lo que el consejo iba a ser durante mucho tiempo. A propuesta de Larrea, en esta sesión

44. Seguimos basándonos en las actas del consejo de ACRDOCRioja.

45. Sobre la peregrinación por distintas dependencias, véase El Rioja histórico (2000), pp. 90 y ss. Véase también Barco Royo, E. (2013) y Coello Martín, C. (2008). 
de 11 de febrero, se envían ejemplares de la "carta geográfica de La Rioja, con una síntesis de la zona, a l'Office International du Vin"46.

La reunión del 14 de abril de 1954 es larga e importante. Hay muchas esperanzas en la exportación, así que se habla del próximo tratado con Holanda, de la tramitación de la marca Rioja en la Oficina Internacional de Berna, de las posibilidades de exportación a Gran Bretaña, del viaje de Larrea a Madrid para activar la tramitación del presupuesto, de los problemas de exportación a Bélgica, sobre lo que Bodegas Bilbaínas advierte que es un mercado caracterizado por la demanda de vinos de bajo precio. El consejo acuerda entregar a "nuestra oficina de Economía Exterior en Bruselas una relación detallada de los agentes exclusivos de los exportadores de La Rioja para que con ellos se constituya una sección especial de la Cámara de Comercio de España en Bélgica". También se debate la petición de Bilbaínas para que su "exclusivista" en Cuba pueda imprimir allí la etiqueta, lo que se niega. En todas las reuniones de este año lo que domina el escenario es la exportación, que empieza a crecer exponencialmente a raíz de la entrada de España en los organismos internacionales y en la alianza bilateral con los Estado Unidos a cambio de las bases militares.

La otra faceta más desarrollada es la publicidad. En 1954, Larrea publica ya varios folletos y artículos en la prensa, por lo que es felicitado por Díaz de Mendívil, el gerente que había hecho sus pinitos antes. Y aparecen los primeros problemas: los vinos de fuera. Larrea sólo puede recordar el reglamento, que permite "operaciones enológicas" para mejorar, pero no para hacer negocio. El 9 de diciembre de 1954, el consejo conoce que se están abriendo los primeros expedientes por fraudes; también las primeras solicitudes aprobadas. Por ejemplo, en la sesión de ese día, se da cuenta de que Bodegas Bilbaínas solicita importar 100.000 litros procedentes de Ricla, en la zona de Cariñena. Se tiene en cuenta que se han producido en viñas propiedad de la bodega y se autoriza, pero se dice que no ha de servir de precedente ${ }^{47}$. En la siguiente reunión, el 25 de enero de 1955, el consejo impone las primeras sanciones, pero ninguna a las grandes bodegas. Entre los sancionados hay siete viticultores de Viana, así como vendedores de Bilbao, Vitoria y Pamplona. Va a empezar la "guerra" contra los almacenistas bilbaínos, que saben que está perdida de antemano, pues los bilbaínos están protegidos por la Cámara de Comercio, que recurre todas las sanciones que reciben y que, obviamente, no pagan. Larrea advierte de las dificultades legales y vuelve a lamentar el desamparo legal de los Consejos Reguladores a la hora de sancionar, pero Díaz de Mendívil saca la artillería y dice que "para mayor efecto psicológico, hay que contar con la guardia civil" que acompañará a los veedores, que deberían detener a los camiones al salir de

46. ARDOCR, Actas, 11 de febrero de 1954.

47. Ídem, Actas, 9 de diciembre de 1954. 
"la zona protegida" de Rioja siempre que no llevaran el certificado del origen del vino. "Así se acuerda en razón a lo cual se realizarán las oportunas gestiones ante la comandancia de la Guardia Civil"48.

El asunto propició algunas escaramuzas, pero los bilbaínos siguieron vendiendo para tabernas y despachos de vinos todo lo que podían, de cualquier procedencia, pero Rioja, bien que primero vendían el cosechero alavés, aunque también sin pagar nada. El 25 de junio de 1955, el malestar se había extendido a los cosecheros alaveses, que se negaban a inscribirse en el consejo. Larrea llegó a acudir a Vitoria, en compañía del director de Agricultura, desplazado a Logroño, para ver al gobernador de Álava, que puso una disculpa para no recibirlos. En la reunión de ese día se habló de visitar al teniente general González Gallarza, riojano y a la sazón ministro del Aire, para que influyera en las actas instancias del Régimen. Se sigue expedientando y sancionando a los almacenistas de Bilbao, que siguen importando vinos alaveses sin pagar el canon, ni nada. A cada uno, cada año 1.000 pesetas, pero se siguen negando a pagar. Pero la "guerra" parece tener una tregua, pues a fines de año se ha inscrito la cooperativa de El Villar de Álava. Más recalcitrantes son los de Elciego. Habrá que esperar unos años, aunque el "problema alavés" resurgirá en numerosas ocasiones hasta nuestros días ${ }^{49}$.

En 1954, Larrea incluye ya un apartado dedicado al Consejo Regulador en las memorias anuales de la Enológica. Todos los años anota sus reflexiones. Es lacónico en su expresión y solo pretende dejar constancia de las actividades de ese "organismo autónomo, ligado solamente por un lazo personal a este centro". Ese organismo "ha remitido su memoria correspondiente a la Superioridad", sigue diciendo Larrea, que recuerda que "Ileva su vida propia". De la actividad del consejo durante ese año, dice: "Régimen Interno. Celebración regular de las sesiones, nombramiento de los veedores, diversas gestiones en los Ministerios de Agricultura y Comercio. Fiscalización. Los veedores comenzaron su actuación, levantando varias actas; se negaron certificados de origen por ser antirreglamentaria su concesión. Administración. Se pidió a la Superioridad una ampliación de créditos para subvenir a las necesidades de los veedores en la forma acordada por la misma Superioridad. No fue concedida. Propaganda. Se insertaron varios asuntos en prensa, se lanzaron circulares y dos folletos de una serie de divulgación de técnica de la industria vitivinícola" ${ }^{\prime 50}$.

En el texto que envió al Boletín de Información del Ministerio de Agricultura, que saldría en su número 45, el ya presidente del Consejo Regulador decía: "A este organismo, como a todos los de su índole, le espera una labor dura y ago-

48. Ídem, Actas, 25 de enero de 1955.

49. El Rioja histórico (2000), Barco Royo, E., passim.

50. AEVEH, memoria de 1954, caja 1095. 
tadora; hay que hacer propaganda y enseñar y divulgar para mejorar las calidades de los vinos de la zona; hay que defender la marca, cerrando el paso a los vinos con nombre de Rioja y procedencias desconocidas; hay que hacer propaganda genérica. Este organismo, completada casi su organización interna, está esperando a que se aprueben sus presupuestos y normas de actuación exterior para comenzar su trabajo. Es de suponer que muy pronto comenzará a actuar, dado el interés del Ministerio de Agricultura por los problemas del vino" ${ }^{\prime 51}$. Es evidente que Larrea establecía un diagnóstico certero sobre el problema de la entrada de vino y uva de fuera que será durante los siguientes años un combate con perdedor anunciado, pues el consejo, a pesar de que impuso sanciones frecuentemente, desde el principio como hemos visto, rara vez pudo llegar hasta el final, pues los bodegueros fraudulentos se amparaban en las leyes de protección de la libertad de comercio, mientras como Larrea se quejará amargamente, la normativa de los Consejos Reguladores no era lo suficientemente dura, ni estaba fundamentada en el campo del derecho para imponerse. Así pues, Larrea tuvo que hacer una clara línea diferenciadora entre aquellos bodegueros que sumaría a su causa por la calidad y aquellos otros a los que solo les movía el afán de vender más y tener más beneficios, lo que casaba perfectamente con la filosofía del régimen que inauguraba en estos años lo que se ha venido en llamar desarrollismo ${ }^{52}$.

En el futuro, el Consejo Regulador se irá consolidando, pues el motor -la exportación- se reanudaba en cuanto el régimen de Franco comenzó a ser aceptado en los organismos internacionales. A la vez, el Sindicato comenzaba su declive; existía, pero su control fue menguando en la medida que el régimen se marcaba metas modernizadoras. Los ministros de Franco de los años sesenta buscaban parecerse a los gobiernos autoritarios, sostenidos por un fuerte crecimiento económico y una envidiable paz social, lo que era muy necesario para atraer al turismo, que iba a convertirse en la principal industria española. Y el turista bebe vino: todavía hoy, Rioja es la marca preferida en las zonas turísticas del Mediterráneo y las islas, pero también tiene una fuerte implantación en el mercado de los países que más turistas aportan, Inglaterra y Alemania. En definitiva, las bases estaban puestas, Consejo y Eve eran claves para acometer la siguiente etapa del Rioja, la de la internacionalización, la meta que dominó la década de los sesenta, el Rioja alegre y feliz que en nada se parecía al vino de luto de las décadas anteriores ${ }^{53}$.

51. Ídem.

52. Pan Montojo, J. (1992), La vitivinicultura en España, 1750-1988. MAPA, Madrid. Serrano Sanz, J. Mª y Pardos, E. (2002), "Los años de crecimiento del franquismo (1959 1975)" Historia económica de España. Siglos X-XX. Crítica, Barcelona.

53. Gómez Urdáñez. J. L. (2015), “El Rioja, 500 años de historia social y cultural de un gran vino español", RIVAR, vol. 2, No 5, pp. 2239. 